\title{
Bioresorbable Vascular Scaffolds \\ - Are We Facing a Time of Crisis or One of Breakthrough? -
}

\author{
Jeehoon Kang, MD; Jung-Kyu Han, MD, PhD; Han-Mo Yang, MD, PhD; \\ Kyung Woo Park, MD, PhD; Hyun-Jae Kang, MD, PhD; \\ Bon-Kwon Koo, MD, PhD; Hyo-Soo Kim, MD, PhD
}

\begin{abstract}
Current 2nd-generation drug-eluting stents (DES) have dramatically improved clinical outcomes after percutaneous coronary intervention for coronary artery disease. However, DES implantation has major long-term limitations related to the permanent presence of foreign material in the coronary artery. Bioresorbable vascular scaffolds (BVS) were designed to overcome this limitation of permanent metal-based DES. However, because of immature manufacturing technology, BVS have several drawbacks, such as the thicker strut, poor deliverability, poor radio-opacity, poor radial strength, and cumbersome procedure to meet the principle of PSP (Preparation, Sizing, and Post-dilatation). Initial studies indicated that BVS outcomes were non-inferior to those of current DES and recent follow-up data of trials have revealed an additional critical drawback, higher rate of scaffold thrombosis, on the top of the existing limitations of BVS. Thus attention must be paid to the appropriate BVS-specific implantation protocols (i.e., PSP), as well as adequate intensity and duration of dual antiplatelet therapy. In any case, current BVS need further technical evolution to replace current metallic DES in routine clinical use.
\end{abstract}

Key Words: Bioresorbable vascular scaffolds; Drug-eluting stents; PSP (Preparation, Sizing, and Post-dilatation); Scaffold thrombosis

\section{History of Drug-Eluting Stent Development}

Since the first coronary angioplasty performed by Andreas Gruntzig in 1977, there has been dramatic progress in percutaneous coronary intervention (PCI) (Figure 1). Although plain old balloon angioplasty (POBA) was originally considered a revolutionary therapeutic strategy for coronary artery disease (CAD), this treatment was associated with an unacceptably high rate (up to $10 \%$ ) of immediate elastic recoil and neointimal proliferation, leading to restenosis. ${ }^{1}$ Specifically, the lack of some form of physical support for the damaged coronary artery with torn media and denuded endothelium after angioplasty contributed to acute closure and chronic vascular remodeling. ${ }^{2}$ Bare-metal stents (BMS) solved the issue of elastic recoil and restenosis, and were accepted as the standard care for CAD. ${ }^{3}$ However, other problems occurred, such as subacute stent thrombosis, technical failure in deployment because of the bulky metal, and a persistent risk of in-stent restenosis (up to $30 \%) .{ }^{4}$ This prompted the development of drug-eluting stents (DES): stents coated with antiproliferative sirolimus or paclitaxel, which substantially reduced the rate of instent restenosis. ${ }^{5}$ As a result, the first-generation DES (Cypher, Cordis, Bridgewater, NJ, USA; and Taxus, Boston Scientific, Natick, MA, USA) became the gold standard for PCI; however in 2006, a striking safety concern emerged regarding the increased risk of stent thrombosis and car- diac death associated with DES implantation. ${ }^{6}$

A better treatment strategy for PCI once again received attention from industry and physicians. New-generation DES show improvement in several major aspects, the first of which is related to the effect of anti-restenotic drugs. Specifically, new-generation DES use drugs such as everolimus, zotarilimus, and biolimus. ${ }^{7}$ The second aspect of improvement is related to the development of new coating polymers that have better biocompatibility and drug release kinetics, ultimately resulting in a significantly lower rate of stent thrombosis. ${ }^{8}$ The third aspect of improvement is related to the development of the stent platform. To ensure accurate deployment, the ideal stent should be easy to deliver and have good radial strength. Based on the massive technical developments in DES technical parameters and implantation technologies, current guidelines recommend DES implantation as the standard care in CAD patients. ${ }^{9}$

\section{Bioresorbable Vascular Scaffold (BVS) as the Next Step in PCI}

Having a foreign material permanently residing in the coronary artery is not an ideal solution in the long term, and there are several inherent drawbacks even with the massive innovations of DES by optimizing the drug kinetics, polymer and the metal platform. ${ }^{10}$ Because of the per-

Received March 2, 2017; revised manuscript received May 29, 2017; accepted June 13, 2017; released online July 6, 2017

Department of Internal Medicine and Cardiovascular Center, Seoul National University Hospital, Seoul, Korea

Mailing address: Hyo-Soo Kim, MD, PhD, Cardiovascular Center, Department of Internal Medicine, Seoul National University

Hospital, 101 Daehak-ro, Jongro-gu, Seoul, 110-744, Korea. E-mail: hyosoo@snu.ac.kr

ISSN-1346-9843 All rights are reserved to the Japanese Circulation Society. For permissions, please e-mail: cj@j-circ.or.jp 


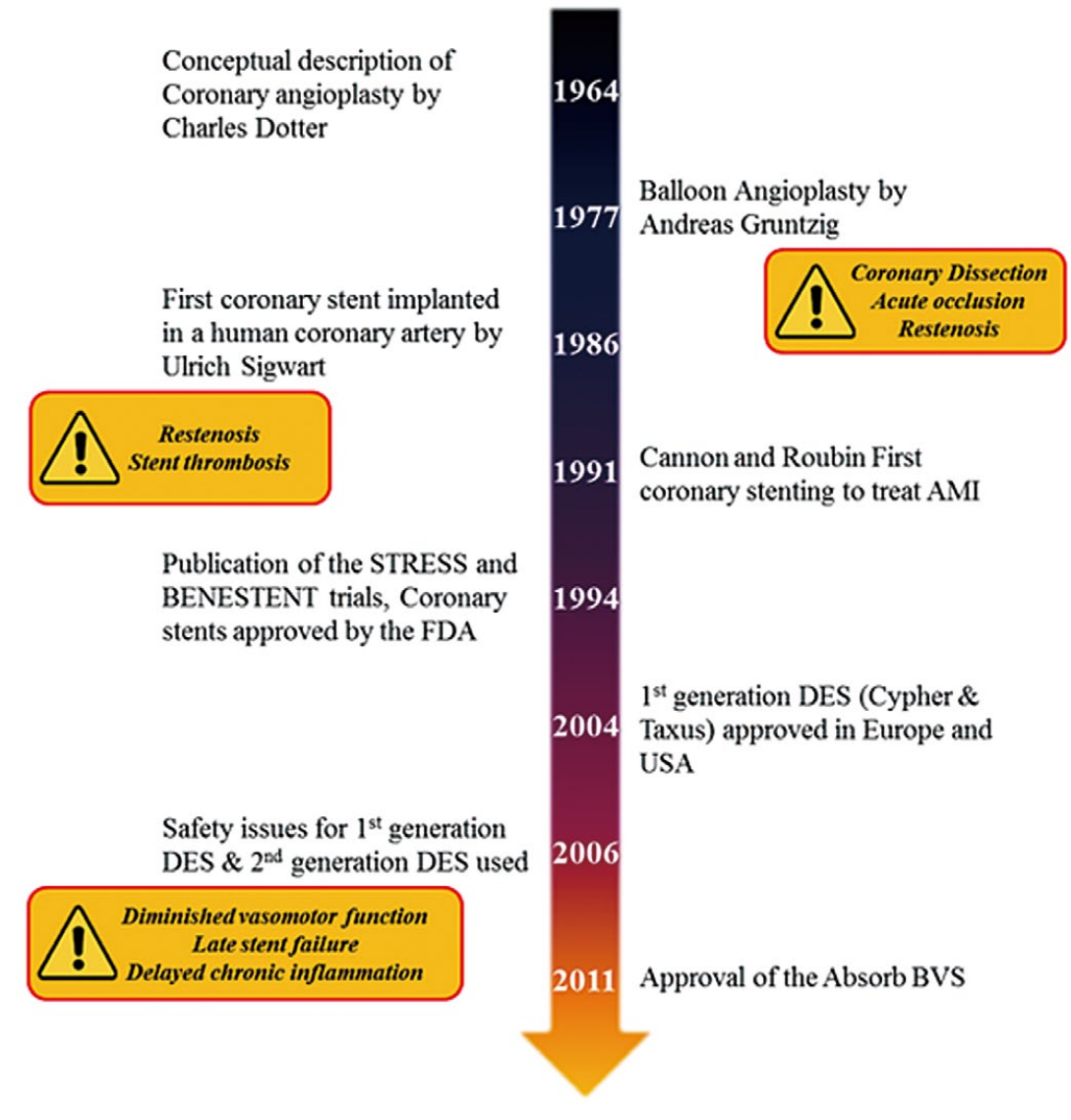

Figure 1. Schematic history of coronary angioplasty. AMI, acute myocardial infarction; BVS, bioresorbable vascular scaffold; DES, drug-eluting stent. manent presence of the metallic platform in the vessel, new-generation DES still carry a risk of diminished vasomotor function, late stent failure, and delayed chronic inflammation caused by the polymer or metal components of the stent. Additionally, the metal cage in the coronary artery wall inhibits compensatory vascular positive remodeling, reduces the options for non-invasive imaging, and limits future treatment options including coronary bypass surgery. ${ }^{11}$ Therefore, the new concept of "leaving nothing behind" emerged, leading to the development of BVS. BVS provide a temporary scaffold that ensures adequate radial support to seal dissection and limit acute recoil and constrictive remodeling, while facilitating the recovery of normal vascular function after stent absorption. Absence of any residual foreign material and restoration of vascular function could reduce the risk of late stent failure and the requirement of prolonged dual antiplatelet therapy (DAPT). BVS technology thus combines the beneficial functions of early PCI strategies into a single platform, by offering effective revascularization as well as suppression of elastic recoil (BMS) and or restenosis (DES), and facilitating the restoration of the treated vessel to a natural state (POBA). ${ }^{12}$ Collectively, by various factor related to this new technology, we can seek to improve PCI clinical outcomes as well as the patients' quality of life (Figure 2).

Although the concept of BVS has been recognized since the 1990 s, only a few BVS have received the Conformité Européene (CE) mark and Food and Drug Administration (FDA) approval (Table 1). The Absorb BVS (Abbott Vas- cular, Santa Clara, CA, USA) is currently the only BVS that has received the CE mark and FDA approval. Absorb BVS consists of a poly-L-lactic acid (PLLA) polymer structure, which, upon implantation, undergoes hydrolysis, degradation, and resorption over a period of $>24$ months (Figure 3). ${ }^{13}$ PLLA exhibits a radial strength approximately 100 -fold lower than that of metallic DES. Therefore, firstgeneration BVS required a significantly thicker strut (by up to $240 \%$ ) to match the current Xience metallic DES in terms of radial strength. ${ }^{10}$ Clinicians expressed concerns even before the release of the clinical trial results, as the significantly thicker strut was expected to severely impede the deliverability and expandability of the BVS.

\section{Angiographic Outcomes From Clinical Trials of BVS}

To date, the Absorb is the most-studied BVS among several that have been tested in clinical trials. ${ }^{14}$ After safety confirmation via the ABSORB cohort A and B studies, a series of registries and randomized controlled trials (RCTs) were conducted to investigate the efficacy and adverse effects of Absorb. A brief overview of the large RCTs is provided.

The ABSORB II study evaluated vasomotion and late loss in 501 patients with de novo coronary lesions, who were randomized to receive either a BVS (335 patients) or an everolimus-eluting stent (EES; 166 patients). ${ }^{15}$ In the ABSORB China trial and EVERBIO II trial, the primary 


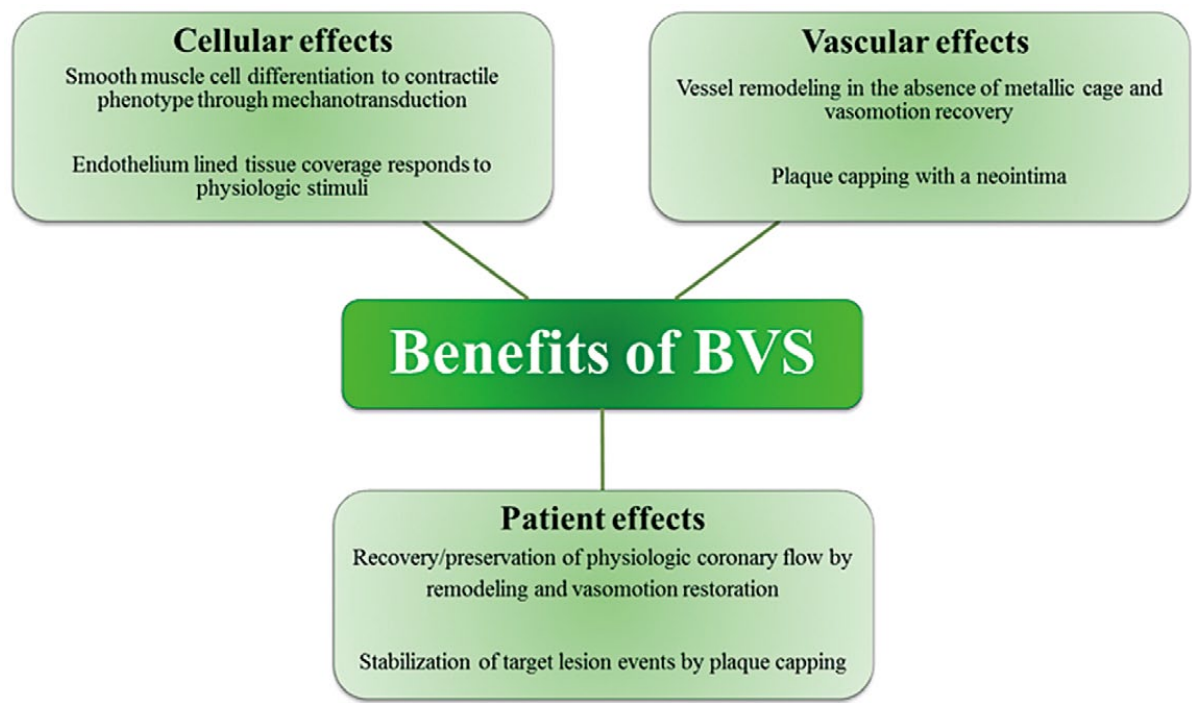

Figure 2. Potential unique benefits of the bioresorbable vascular scaffold (BVS).

\begin{tabular}{|c|c|c|c|c|c|c|c|c|}
\hline $\begin{array}{l}\text { BVS } \\
\text { name }\end{array}$ & Manufacturer & $\begin{array}{l}\text { Regulatory } \\
\text { approval } \\
\text { status }\end{array}$ & Material & $\begin{array}{c}\text { Strut } \\
\text { thickness }\end{array}$ & Design & Drug & $\begin{array}{l}\text { Resorption } \\
\text { time }\end{array}$ & $\begin{array}{l}\text { Landmark } \\
\text { trials }\end{array}$ \\
\hline $\begin{array}{l}\text { Absorb } \\
\text { BVS/GT1 }\end{array}$ & $\begin{array}{c}\text { Abbot } \\
\text { vascular }\end{array}$ & $\begin{array}{l}\text { CE Mark, } \\
\text { FDA } \\
\text { Approval }\end{array}$ & PLLA & $157 \mu \mathrm{m}$ & $\begin{array}{c}\text { In-phase } \\
\text { hoops with } \\
\text { straight links }\end{array}$ & Everolimus & $\sim 36$ months & $\begin{array}{c}\text { ABSORB } \\
\text { II/III/Japan/China } \\
\text { RCT }\end{array}$ \\
\hline DESolve & Elixir & CE Mark & PLA-based & $150 \mu \mathrm{m}$ & $\begin{array}{c}\text { In-phase } \\
\text { hoops with } \\
\text { straight links }\end{array}$ & Novolimus & $\leq 24$ months & $\begin{array}{l}\text { DESolve NX } \\
\text { Registry-based } \\
\text { study }\end{array}$ \\
\hline ART $18 Z$ & Terumo & CE Mark & PDLLA & $160 \mu \mathrm{m}$ & $\begin{array}{l}\text { Creep-resistant } \\
\text { hinge }\end{array}$ & None & 18-24 months & $\begin{array}{l}\text { ARTDIVA } \\
\text { FIM trial }\end{array}$ \\
\hline Magmaris & Biotronik & CE Mark & $\begin{array}{l}\text { Magnesium } \\
\text { Alloy }\end{array}$ & $150 \mu \mathrm{m}$ & 6 crown & Sirolimus & 9-12 months & $\begin{array}{l}\text { BIOSOLVE } \\
\text { II FIM trial }\end{array}$ \\
\hline
\end{tabular}

BVS, bioresorbable vascular scaffold; CE, Conformité Européene; FDA, Food and Drug Administration; FIM, First-in-man; PLLA, poly-L-lactic acid; PLA, polylactic acid; PDLLA, poly-D-L-lactic acid; RCT, randomized clinical trials; ST, scaffold thrombosis.

\begin{tabular}{|c|c|c|c|c|}
\hline Drug & Scaffold Material & $\begin{array}{l}\text { Scaffold Delivery } \\
\text { System (SDS) }\end{array}$ & Scaffold Design & Long -Term Benefit \\
\hline Everolimus & $100 \%$ Poly-L-Lactic Acid & Absorb SDS & MULTI-LINK & Restores Vessel \\
\hline $\begin{array}{l}\text { - Low late loss } \\
\text { - Low Target lesion } \\
\text { revascularization }\end{array}$ & $\begin{array}{l}\text { Biocompatible through } 100 \% \\
\text { resorption } \\
\text { - Mechanically stable through } \\
\text { neointimal maturation } \\
\text { - Translucent, radiolucent and } \\
\text { not ferromagnetic for OCT, } \\
\text { CT and MR compatibility }\end{array}$ & $\begin{array}{l}\text { - Semi-compliant } \\
\text { - Larger struts affect } \\
\text { profile }\end{array}$ & $\begin{array}{l}\text { - Radial support } \\
\text { equal to Xience } \\
\text { - Optimal footprint } \\
\text { for plaque support } \\
\text { - Coverage complete } \\
\text { by } 6 \text { months } \\
\text { - More sizes needed }\end{array}$ & $\begin{array}{l}\text { - Resorption time } \\
\text { optimizes support vs. } \\
\text { healing } \\
\text { - Vasomotion restoration }\end{array}$ \\
\hline
\end{tabular}

Figure 3. Characteristics of the Absorb bioresorbable vascular scaffold (Abbott Vascular, Santa Clara, CA, USA). CT, computed tomography; OCT, optical coherence tomography; MR, magnetic resonance. 

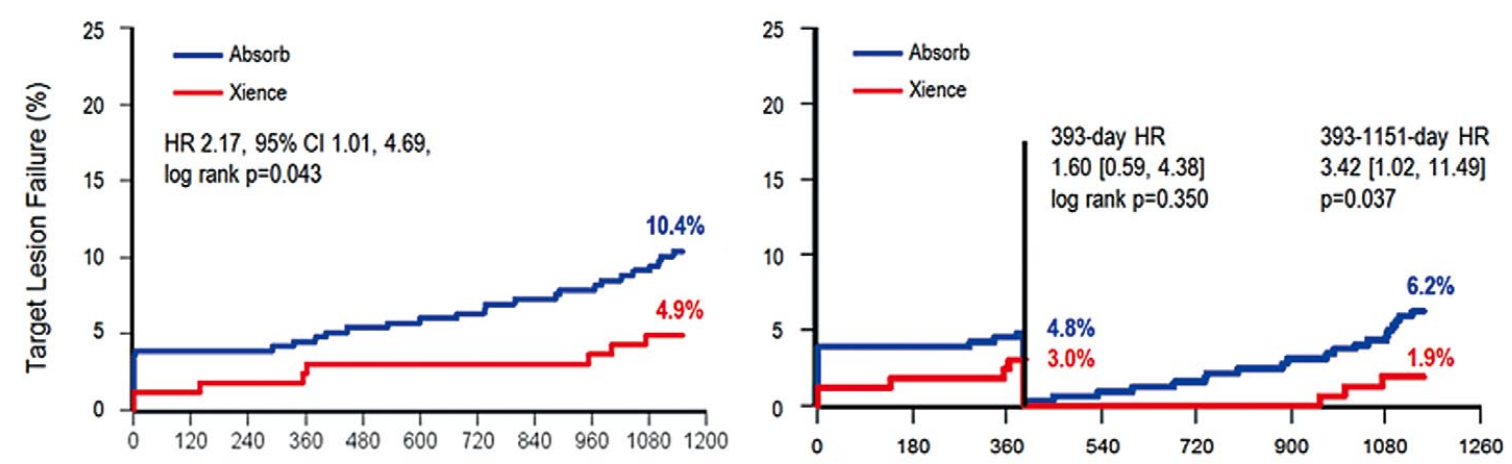

Time to event (days)

Figure 4. Target lesion failure (TLF) for 3 years in the ABSORB II trial. Cl, confidence interval; HR, hazard ratio.

outcome was angiographic late lumen loss in 480 patients (BVS, 241 patients; EES, 239 patients) and 240 patients (BVS, 80 patients; DES, 160 patients), respectively. ${ }^{\mathbf{1 6}, 17}$ The ABSORB Japan trial enrolled 400 patients (BVS, 266 patients; EES, 134 patients) and evaluated the rate of target lesion failure (TLF) at the 1-year follow-up, representing a composite of cardiac death, target vessel-related myocardial infarction, ischemia-driven target lesion revascularization. ${ }^{18}$ The ABSORB III trial was the largest RCT, enrolling 2,008 patients (BVS, 1,332 patients; EES, 686 patients), and also evaluated TLF at the 1-year followup. ${ }^{19}$ Finally, the TROFI II trial assessed arterial healing, expressed as an optical frequency domain imaging-derived healing score, in 191 patients with ST-elevation myocardial infarction (BVS, 95 patients; EES, 96 patients). ${ }^{20}$ These studies demonstrated that the outcomes of BVS were not inferior to those of currently used EES. Despite these promising results, interventional cardiologists remain unconvinced and are not yet comfortable applying this novel technology to daily practice because of several important concerns. First, the clinical results for BVS were comparable to those for EES, but various secondary angiographic outcomes of BVS were inferior to EES. Second, $\mathrm{BVS}$ raised concerns related to the increased rate of scaffold thrombosis (ST), whereas EES reassured with excellent long-term safety. Third, the specific protocol to deploy BVS emerged as very important for procedural success. However, the technique was unfamiliar to clinicians, and became a burden on operators because it requires a longer procedure time, more radiation exposure, more usage of devices, and more cost. Lastly, the indication for BVS implantation is limited by lesion complexity and vessel size.

Regarding acute angiographic outcomes, interim analyses of RCT results have shown slightly disappointing results. The ABSORB II trial indicated that, at the 1-year follow-up, the Absorb BVS provided a smaller acute gain than did EES (BVS, $1.15 \pm 0.38 \mathrm{~mm}$ vs. EES, $1.46 \pm 0.38 \mathrm{~mm}$, $\mathrm{P}<0.001)$. This finding was confirmed by intravascular ultrasound (IVUS) analysis, which revealed smaller acute gain in the minimal lumen area by BVS (BVS, $2.85 \pm 1.25 \mathrm{~mm}^{2}$ vs. EES, $\left.3.60 \pm 1.34 \mathrm{~mm}^{2}, \mathrm{P}<0.001\right)$. Similar trends regarding poor acute gain with BVS were noted in the ABSORB China trial (BVS, $1.51 \pm 0.03 \mathrm{~mm}$ vs. EES, $1.59 \pm 0.03 \mathrm{~mm}$, $\mathrm{P}=0.04$ ), ABSORB Japan trial (BVS, $1.46 \pm 0.40 \mathrm{~mm}$ vs.
EES, $1.65 \pm 0.40 \mathrm{~mm}, \mathrm{P}<0.001)$, and ABSORB III trial (BVS, $1.45 \pm 0.45 \mathrm{~mm}$ vs. EES, $1.59 \pm 0.44 \mathrm{~mm}, \mathrm{P}<0.001$ ). Furthermore, a patient-level meta-analysis of the early outcomes of Absorb implantation also showed a smaller acute gain in the BVS group (BVS, $1.41 \pm 0.45 \mathrm{~mm}$ vs. EES, $1.58 \pm 0.43 \mathrm{~mm}, \mathrm{P}<0.001) .{ }^{21}$ In other studies, however, indevice acute gain was found to be similar between Absorb and EES in the EVERBIO II trial (BVS, $1.97 \pm 0.66 \mathrm{~mm}$ vs. EES, $2.09 \pm 0.49 \mathrm{~mm}, \mathrm{P}=0.47$ ) and the TROFI II trial (BVS, $2.16 \pm 0.52 \mathrm{~mm}$ vs. EES, $2.21 \pm 0.56 \mathrm{~mm}, \mathrm{P}=0.57)$. Overall, acute gain after PCI using BVS was smaller than (or similar to) that after PCI using EES, whereas acute recoil in the BVS groups was slightly higher than (or similar to) that in the EES groups.

Regarding late lumen loss, the BVS was expected to retain mechanical stability during the early follow-up period. However, RCTs evaluating late lumen loss at 6-13 months after the index procedure reported conflicting results. Specifically, larger in-device late loss was reported for the BVS group than for the EES group in the ABSORB China trial (BVS, $0.23 \pm 0.03 \mathrm{~mm}$ vs. EES, $0.10 \pm 0.02 \mathrm{~mm}$, $\mathrm{P}<0.001$ ) and the TROFI II trial (BVS, $0.17 \pm 0.24 \mathrm{~mm}$ vs. EES, $0.08 \pm 0.28 \mathrm{~mm}, \mathrm{P}=0.024)$, whereas similar values between the BVS and EES groups were noted in the ABSORB Japan trial (BVS, $0.19 \pm 0.31 \mathrm{~mm}$, vs. EES, $0.16 \pm 0.33 \mathrm{~mm}, \mathrm{P}=0.35$ ) and the EVERBIO II trial (BVS, $0.28 \pm 0.39 \mathrm{~mm}$ vs. EES, $0.24 \pm 0.32 \mathrm{~mm}, \mathrm{P}=0.40$ ). Although the studies differ in terms of the statistical significance of the results, the absolute values of late lumen loss were consistently slightly greater in the BVS groups than in the EES groups.

\section{Clinical Outcomes of BVS Implantation}

To date, all 6 RCTs of BVS have reported 1-year clinical outcomes. TLF event rates were similar between the BVS and EES groups in all 6 RCTs: the ABSORB China trial (BVS, 3.4\% vs. EES, 4.2\%, P=0.62), the ABSORB Japan trial (BVS, $4.2 \%$ vs. EES, $3.8 \%, \mathrm{P}=0.85$ ), the ABSORB II trial (BVS, $4.8 \%$ vs. EES, $3.0 \%, \mathrm{P}=0.35$ ), the ABSORB III trial (BVS, $7.8 \%$ vs. EES, $6.1 \%, \mathrm{P}=0.16$ ), the EVERBIO II trial (at 9 months; BVS, $12 \%$ vs. EES, 14\%, $\mathrm{P}=0.68$ ), and the TROFI II trial (at 6 months; BVS, $1.1 \%$ vs. EES, $0.0 \%$, $\mathrm{P}$ not significant). Although these initial results seemed to 
Table 2. Previous Meta-Analyses of Bioresorbable Vascular Scaffolds vs. Drug-Eluting Stents

\begin{tabular}{|c|c|c|c|c|c|}
\hline & $\begin{array}{l}\text { Included } \\
\text { studies* }\end{array}$ & No. of patients & $\begin{array}{l}\text { Follow-up } \\
\text { duration }\end{array}$ & ST rate & $\begin{array}{c}\text { Comment on } \\
\text { analyzed studies }\end{array}$ \\
\hline $\begin{array}{l}\text { Cassese et al } \\
(2016)^{43}\end{array}$ & $(1-6)$ & $\begin{array}{l}\text { Total: } 3,738 \text { patients } \\
\text { from } 6 \text { RCTs } \\
\text { BVS: } n=2,337 \\
\text { EES: } n=1,401\end{array}$ & $\begin{array}{c}12 \\
\text { months }\end{array}$ & $\begin{array}{l}\text { *Definite or probable ST: BVS vs. EES: } \\
29 / 2,309(1.3 \%) \text { vs. } 7 / 1,382(0.5 \%) \\
\text { OR } 1.99,95 \% \mathrm{Cl}: 1.00-3.98, \mathrm{P}=0.05 \\
\text { (Between } 1 \text { and } 30 \text { days after implantation: } \\
\text { OR } 3.11,95 \% \mathrm{Cl} 1.24-7.82, \mathrm{P}=0.02)\end{array}$ & $\begin{array}{l}\text { Only included RCTs } \\
\text { comparing BVS and } \\
\text { EES }\end{array}$ \\
\hline $\begin{array}{l}\text { Lipinski et al } \\
(2016)^{26}\end{array}$ & $\begin{array}{l}(1),(5) \\
(7-26) \\
(34-36)\end{array}$ & $\begin{array}{l}\text { Total: } 10,510 \text { patients } \\
\text { (2 RCTs, } 7 \text { comparative } \\
\text { observational studies, } \\
16 \text { single-arm studies) } \\
\text { BVS: } n=8,351 \\
\text { DES: } n=2,159\end{array}$ & $\begin{array}{l}6.4 \pm 5.1 \\
\text { months }\end{array}$ & $\begin{array}{l}\text { *Total BVS arm: } \\
\text { Acute ST: } 0.27 \% \text {, subacute ST: } 0.57 \% \\
\text { *9 studies comparing BVS and EES } \\
\text { Definite or probable ST: OR } 2.06,95 \% \mathrm{Cl} \text { : } \\
\text { 1.07-3.98, P=0.03 } \\
\text { Definite ST: OR } 1.91,95 \% \mathrm{Cl}: 0.82-4.46 \\
\text { P=0.13 }\end{array}$ & $\begin{array}{l}\text { Included RCTs, } \\
\text { single-arm prospective } \\
\text { registry data, } \\
\text { retrospective analysis } \\
\text { data, and presentation } \\
\text { slides of late-breaking } \\
\text { clinical trials }\end{array}$ \\
\hline $\begin{array}{l}\text { Stone et al } \\
(2016)^{22}\end{array}$ & $(1-4)$ & $\begin{array}{l}\text { Total: } 3,389 \text { patients } \\
\text { from } 4 \text { RCTs } \\
\text { BVS: } n=2,164 \\
\text { EES; } n=1,225\end{array}$ & $\begin{array}{c}12 \\
\text { months }\end{array}$ & $\begin{array}{l}\text { *Definite or probable ST: BVS vs. EES: } \\
28 / 2,130(1.3 \%) \text { vs. } 7 / 1,204(0.6 \%) \\
\text { OR } 2.09,95 \% \mathrm{Cl}: 0.92-4.75, \mathrm{P}=0.08 \\
\text { (Between } 0 \text { and } 30 \text { days after implantation: } \\
\text { OR } 1.76,95 \% \mathrm{Cl}: 0.72-4.34, \mathrm{P}=0.22)\end{array}$ & $\begin{array}{l}\text { Only included RCTs } \\
\text { comparing BVS and } \\
\text { EES, studies with a } \\
\text { 12-month follow-up, } \\
\text { and patients with stable } \\
\text { CAD or stabilized ACS }\end{array}$ \\
\hline $\begin{array}{l}\text { Zhang et al } \\
(2016)^{44}\end{array}$ & $\begin{array}{l}(1-12) \\
(16-17) \\
(20-22) \\
(27-35) \\
(37-44)\end{array}$ & $\begin{array}{l}\text { Total: } 16,896 \text { patients } \\
\text { (6 RCTs, } 6 \text { comparative } \\
\text { observational studies, } \\
32 \text { single-arm studies) } \\
\text { BVS: } n=13,416 \\
\text { EES: } n=3,480\end{array}$ & $\begin{array}{l}10.5 \\
\text { months }\end{array}$ & $\begin{array}{l}\text { *Total BVS arm: } \\
\text { Definite or probable ST: } 1.5 \text { events per } \\
100 \text { PYs } \\
\text { *12 studies comparing BVS and EES } \\
\text { Definite or probable ST: BVS vs. EES: } \\
47 / 3,628(1.3 \%) \text { vs. } 19 / 3,022(0.6 \%) \\
\text { OR } 2.17,95 \% \text { Cl: } 1.25-3.77, \mathrm{P}=0.006 \\
\text { Subacute ST: OR } 3.53,95 \% \mathrm{Cl}: 1.09- \\
11.44, \mathrm{P}=0.035\end{array}$ & $\begin{array}{l}\text { Included RCTs, } \\
\text { observational studies, } \\
\text { abstracts involving at } \\
\text { least } 40 \text { patients with } \\
\text { CAD }\end{array}$ \\
\hline $\begin{array}{l}\text { Mukete et al } \\
(2016)^{45}\end{array}$ & $\begin{array}{l}(1-4) \\
(7-8)\end{array}$ & $\begin{array}{l}\text { Total: } 5,588 \text { patients } \\
\text { from } 6 \text { RCTs } \\
\text { BVS: } n=3,253 \\
\text { EES: } n=2,315\end{array}$ & $\begin{array}{c}12 \\
\text { months }\end{array}$ & $\begin{array}{l}\text { *Definite or probable ST: BVS vs. EES } \\
\text { 43/3,253 (1.3\%) vs. } 13 / 2,315(0.6 \%) \\
\text { OR } 2.10,95 \% \text { Cl: } 1.13-3.87, P=0.02\end{array}$ & $\begin{array}{l}\text { Only included RCTs } \\
\text { comparing BVS and } \\
\text { EES, propensity } \\
\text { score-matched } \\
\text { studies comparing } \\
\text { BVS and EES, with a } \\
\text { 12-month follow-up }\end{array}$ \\
\hline
\end{tabular}

CAD, coronary artery disease; DES, drug-eluting stent; EES, everolimus-eluting stent; PY, person-years. Other abbreviations as in Table 1.

\section{*Description of included studies}

- RCT or propensity score-matching design:

- (1) ABSORB II, Lancet 2015, (2) ABSORB III, NEJM 2015, (3) ABSORB Japan, EHJ 2015, (4) ABSORB China, JACC 2015, (5) EVERBIO II, JACC 2015, (6) TROF II, EHJ 2015, (7) ABSORB EXTEND, Eurointervention 2015, (8) BVS-EXAMINATION, JACC Cardiovasc Interv 2015.

- Single-arm prospective registry data, retrospective data:

- (9) ABSORB, Circ Cardiovasc Interv 2012, (10) AMC, Eurointervention 2015, (11) ASSURE Eurointervention 2015, (12) BVA-RAI, Am J Cardiol 2015, (13) BVS STEMI, EHJ 2014, (14) CTO-ABSORB, Eurointervention 2015, (15) GABI-R, Cardiovasc Revasc Med 2016 (16) GHOST-EU, Eurointervention 2015, (17) POLAR-ACS, Pol Arch Med Wewn 2014, (18) PRAGUE-19, EHJ 2014, (19) Robaei et al, Heart Lung Circ 2015, (20) Costopoulos et al, Catheter Cardiovasc Interv 2015, (21) Gori et al, JACC Cardiovasc Interv 2014, (22) Jaguszewski et al, Clin Res Cardiol 2014, (23) Kajiya et al, Eurointervention 2013, (24) Mattesini et al, JACC Cardiovasc. Interv 2014 (25) Ojeda et al, Am J Cardiol 2015, (26) Wiebe et al, Clin Res Cardiol 2014, (27) ESHC-BVS registry, J Invasive Cardiol. 2015, (28) Haji et al, Heart Lung Circ 2015, (29) Kabir et al, Indian Heart J 2015, (30) Moscarella et al, Int J Cardiol 2015, (31) Romero et al, EHJ 2015, (32) Sainsous et al, Arch Cardiovasc Dis 2015, (33) Teeuwen et al, Clin Trials Regul Sci Cardiol 2015.

- Abstracts:

- (34) ABSORB FIRST, Abstr. EuroPCR 2015, (35) BVS EXPAND, Abstr. EuroPCR 2014, (36) REPARA, Abstr. EuroPCR 2015, (37) Cuculi, Abstr. EuroPCR 2015 (38), Dalos et al, Abstr. EuroPCR 2015 (39) De Waha et al, Abstr. EuroPCR 2015, (40) Khripun et al, Abstr. EuroPCR 2015, (41) Maasstad Absorb registry, Abstr. EuroPCR 2015, (42) Camacho et al, Abstr. EuroPCR 2015, (43) El Khoury et al, Abstr. TCT 2014, (44) Elabbassi, Abstr. EuroPCR 2014.

guarantee an optimistic future for BVS, the sample size of each study was too small to confer clinical significance to the findings, and further analysis raised concerns regarding the safety of BVS, which will be discussed later in this review.

The 3-year follow-up outcomes of the ABSORB II trial, which were published recently, represent the first mid-term follow-up results of the initial RCTs of BVS use. ${ }^{21}$ This study measured angiographic late lumen loss and vasomotion that were evaluated in terms of the change in mean lumen diameter, assessed by quantitative coronary angiography pre- and post-administration of intracoronary nitrate. Vasomotor reactivity at 3 years post-PCI did not differ significantly between the Absorb BVS and EES groups (BVS, $0.047 \pm 0.109 \mathrm{~mm}$ vs. EES, $0.056 \pm 0.117 \mathrm{~mm}, \mathrm{P}=0.49$ ), whereas late luminal loss was larger in the Absorb group (BVS, $0.37 \pm 0.45 \mathrm{~mm}$ vs. EES, $0.25 \pm 0.25 \mathrm{~mm}, \mathrm{P}<0.001$ ). Additionally, the TLF rate was significantly higher in the BVS group ( $10 \%$ vs. $5 \%, \mathrm{P}=0.043$; Figure 4). An interesting finding was that the BVS arm had significantly higher rates of target vessel-related myocardial infarction (BVS, 7\% [23/325] vs. EES, $1 \%[2 / 161], \mathrm{P}=0.006)$ and definite or probable ST (BVS, 3\% [9/320] vs. EES, 0\% [0/164], $\mathrm{P}=0.033$ ). In particular, very late ST occurred in 6 patients with BVS, but in none of the patients with EES. Also, the 2-year follow-up data of the ABSORB III trial were 


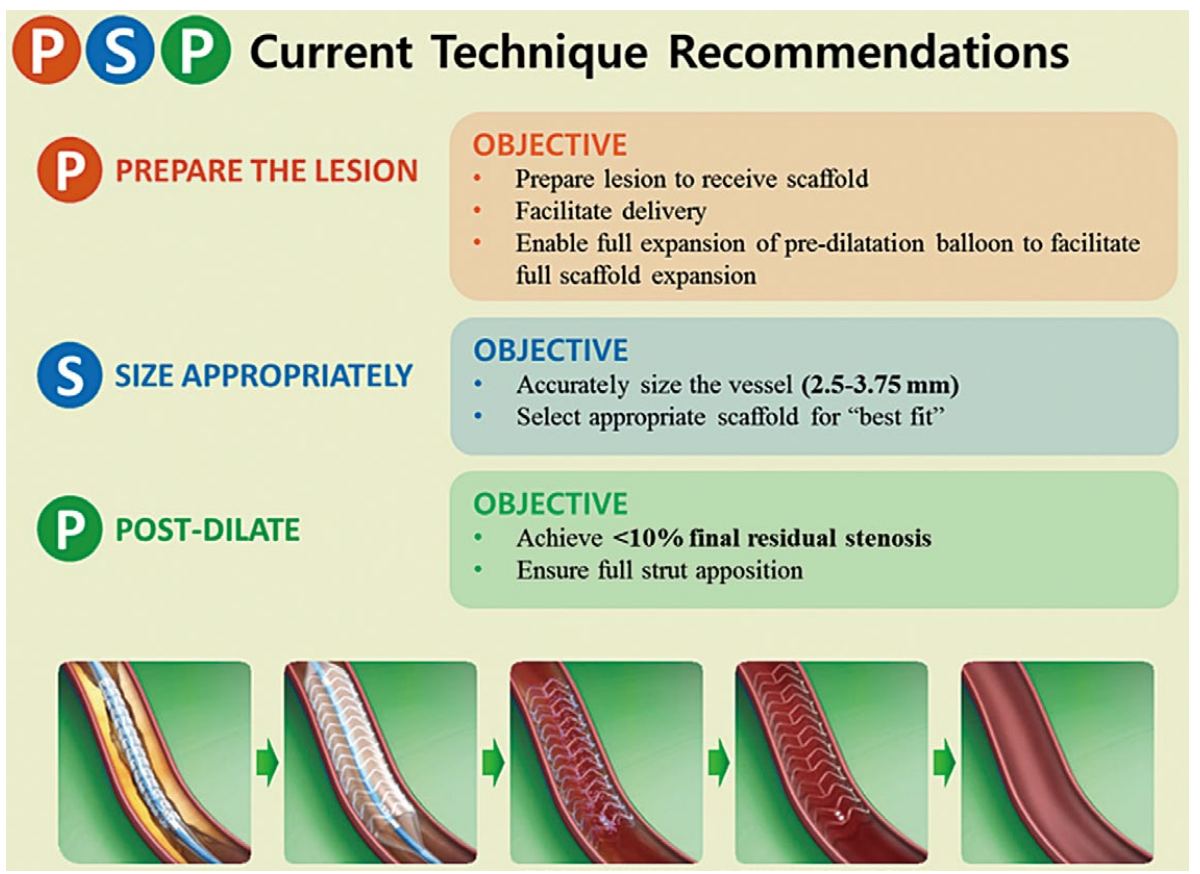

Figure 5. Curent BVS-specific PSP technique. BVS, bioresorbable vascular scaffold.

recently reported at the American College of Cardiology 2017 Scientific Sessions. The cumulative 2-year TLF rates were higher with Absorb than with EES (11.0\% vs. 7.9\%, $\mathrm{P}=0.03$ ), but in patients with appropriately sized vessels (reference vessel diameter $\geq 2.25 \mathrm{~mm}$ ) the difference was smaller $(9.4 \%$ vs $7.0 \%, \mathrm{P}=0.11)$. These results raised the safety concerns related to BVS implantation, with particular focus on the dissolution or breakdown of the scaffold during resolution within the first 3 years after PCI. Longerterm data from the ABSORB III/IV program will determine whether better patient/lesion selection and technique have improved outcomes compared with EES.

\section{Scaffold Thrombosis After BVS Implantation}

As mentioned before, clinical event rates in the BVS arms were similar those in the EES arms in all 6 RCTs evaluating the performance of Absorb (ABSORB II, ABSORB III, ABSORB China, ABSORB Japan, EVERBIO II, TROFI II). Additionally, a recent patient-level pooled meta-analysis including 3,389 patients with stable CAD or stabilized acute coronary syndrome reported that the 1-year relative rates of patient-oriented composite endpoints did not differ significantly between the BVS and EES arms. ${ }^{22}$ Despite the promising results, there exists a concern related to the increased rate of ST. The ABSORB II trial reported increased definite or probable scaffold or stent thrombosis in the BVS group at the 3-year follow-up (BVS, 2.8\% [9/320] vs. EES $0.0 \%$ [0/159], $\mathrm{P}=0.03) .{ }^{21}$ Also, several studies based on data from the GHOST-EU and BVS-EXAMINATION registries have reported numerically higher ST rates after BVS implantation than stent thrombosis rates reported in previous large-scale registries of DES $(2.1 \%$ in the GHOST-EU registry, $2.4 \%$ in the BVS-EXAMINATION registry). ${ }^{23-25}$ Meta-analyses have reported consistent results. Specifically, Stone et al reported a marginally significant higher stent thrombosis event rate in the BVS arm compared with the EES arm at the 1-year follow-up (BVS: $1.3 \%$ [28/2,310] vs. EES, 0.6\% [7/1204], P=0.08). ${ }^{22}$ Additionally, a meta-analysis including 10,510 patients from RCTs and registries concluded that those with implanted BVS were at a significantly higher risk of ST than those with EES (odds ratio, 2.06; 95\% confidence interval, 1.31$3.22 ; \mathrm{P}=0.03){ }^{26}$ Table 2 lists the various meta-analyses that have reported the overall risk of BVS thrombosis, which was significantly higher than that of EES thrombosis.

Several unique characteristics of BVS may contribute to the increased risk of ST. Current BVS have struts that are thicker $(150 \mu \mathrm{m})$ than the struts of 2 nd-generation DES in order to maintain radial strength and prevent acute recoil after deployment. ${ }^{27}$ However, increased strut thickness has resulted in poor crossing profile, increased susceptibility to strut fracture, and delayed endothelial healing over the protruding struts. As a consequence, BVS are more prone to thrombosis, which is caused by the loss of laminar flow and greater turbulent flow around the struts and suboptimal deployment. Also, distinctive morphological abnormalities of BVS are suspected as possible causes of ST. A recent review analyzed cases of ST assessed by intracoronary imaging, reporting that malapposition, incomplete lesion coverage, and underexpansion were the most frequent findings in acute/subacute ST, whereas malapposition, late discontinuity, and peri-strut low-intensity areas were the predominant features in late/very late cases. ${ }^{28}$ Moreover, it has been suggested that the mechanisms behind early and very late ST differ; underexpansion of the BVS is the main cause in early ST, whereas malapposition with residual stenosis or uncovered late discontinuity caused by the scaffold resorption process is the main cause of very late ST. ${ }^{29}$ 
These drawbacks in the physical properties of BVS made the optimal deployment technique very important, such as the use of intravascular imaging and high-pressure post-dilation. ${ }^{14}$ In a subgroup analysis of the ABSORB II study, Sotomi et al highlighted the importance of aggressive post-dilatation in BVS deployment ${ }^{30}$ Regarding the stenting technique, Puricel et al stated that the Absorbspecific protocol significantly reduced the thrombosis rate compared with that noted during trials of early BVS (12month ST: $3.3 \%$ vs. $1.0 \%, \mathrm{P}=0.023){ }^{31}$ The results of optimal stent implantation using the "PSP" method (Prepare the lesion, Size appropriately, Post-dilate) were presented at the 2016 Transcatheter Cardiovascular Therapeutics meeting (Figure 5). Only 10.4\% $(292 / 2,815)$ of the patients enrolled in the 5 RCTs of Absorb received optimal PSP, and this population showed decreased target lesion-related outcomes and ST (1-3 year TLF: $7.1 \%$ vs. $0.0 \%, 1-3$ year ST: $2.0 \%$ vs. $0.0 \%) .{ }^{32}$ In the early Absorb RCTs, postdilation was performed in less than 2 out of 3 patients (ABSORB II, 61\%; ABSORB III, 65.5\%; ABSORB Japan, 82.2\%; ABSORB China, 63.0\%; TROFI II, 50.5\%). Thus, one may conclude that the clinical outcomes of BVS implanted according to early DES implantation protocols are likely to be somewhat worse than those of BVS implanted according to the new PSP method. More recent registries have applied the PSP technique to most patients, leaving expectations of better outcomes.

\section{BVS Implantation for Complex Lesions}

Most RCTs of BVS have enrolled relatively stable patients with simple lesions. The ABSORB trials included patients with minimal comorbidities and excluded patients with histories of renal insufficiency, cancer, congestive heart failure, depressed systolic function, or ongoing myocardial infarction. Moreover, they enrolled only simple lesions (e.g., 1 de novo native lesion per epicardial artery, with $50-100 \%$ diameter stenosis and a TIMI flow $\geq 1$ ) and excluded long lesions, left main lesions, ostial lesions, bifurcation lesions, and lesions with excessive tortuosity (from extreme angulation or heavy calcification). Therefore, the RCT population is distinctly different from the patient population referred for PCI in the clinical setting, especially in the current era, when patients with more complex coronary lesions are candidates for PCI.

Overlapping implantation of BVS is also an issue that should be settled before applying BVS to complex coronary lesions. Stent overlapping is known to increase local turbulence, which can induce inflammation and delay endothelial healing. However, in an analysis of the GHOST-EU registry and RAI registry, overlapping BVS showed no difference in clinical outcomes compared with not overlapping. ${ }^{33,34}$ Specifically, Tarantini et al reported that the BVS overlapping technique (marker-to-marker, marker-overmarker, marker-inside-marker) and reason for performing BVS overlapping (planned or bail-out strategy) had no influence on clinical outcomes. ${ }^{34}$ Despite these results, further analysis is needed on the effect of BVS overlapping.

Some recent studies have reported acceptable outcomes of BVS implantation in an extended population of candidates (i.e., patients with ST-elevation myocardial infarction or with complex lesions such as bifurcation or left main disease), indicating that the spectrum of BVS indication may be wider ${ }^{35}$ Regarding long lesions $(>24 \mathrm{~mm})$, in 1,002 patients the 1-year follow-up showed that DOCE occurred in 9.9\% (95 patients) and definite/probable ST was $0.9 \%{ }^{36}$ The outcomes related to off-label indications of BVS will be assessed in large-scale, all-comer registries such as the FRANCE-ABSORB registry (ClinicalTrials. gov identifier: NCT02238054) and the FEAST Russia Registry (ClinicalTrials.gov identifier: NCT02707783), which are ongoing. The performance of BVS and EES will be compared in patients at high risk of restenosis, enrolled in the COMPARE-ABSORB RCT (ClinicalTrials.gov identifier: NCT02486068). Unlike the initial ABSORB studies, the ongoing ABSORB EXTEND registry enrolled a more diverse subject population, with greater lesion complexity ${ }^{37}$ Data from these studies will provide additional insight regarding the role of BVS in complex lesions. More data on the long-term safety and efficacy of BVS, together with improvements in scaffold design, are warranted before patients with multiple comorbidities and complex lesions can be routinely indicated for BVS implantation.

\section{BVS Implantation for Vulnerable Plaques}

Traditional strategies for the treatment of CAD were aimed at obstructive atherosclerotic lesions, to evaluate significant stenosis and relieve the current ischemic burden. However, these methods had limited effect in preventing future clinical events mainly caused by vulnerable plaques (i.e., lesions having a high likelihood of rupture). Therefore, more than just evaluating the stenosis, early identification of vulnerable plaques (using IVUS, optical coherence tomography (OCT) or coronary $\mathrm{CT}$ angiography etc.) has gained great interest.

With regard to the Absorb BVS, it has been established that a neointimal layer is built up to form a "de novo" fibrotic cap after the scaffold is degraded. ${ }^{38}$ This mechanism could 'seal off' the vulnerable plaque and prevent future clinical events. But such a strategy to seal off vulnerable plaque using BVS would not be promising because of the safety and/or ST concerns. Upcoming studies such as the PROSPECT ABSORB (ClinicalTrials.gov Identifier: NCT02171065) will evaluate the ability of BVS to safely seal a vulnerable plaque. The PROSPECT ABSORB RCT will examine whether BVS plus guideline-directed medical therapy can increase the minimal lumen diameter compared with guideline-directed medical therapy alone, after 2 years.

\section{Restenosis After BVS Implantation}

Restenosis is one of the most common causes of stent failure. However, because of the short experience of BVS implantation, limited data are available in the literature on this topic. Many mechanisms have been suggested to explain BVS failure, including neointimal hyperplasia, neoatherosclerosis, BVS collapse, scaffold fracture, edge phenomenon and late dismantling. ${ }^{39}$ If the mechanism of BVS restenosis was similar to that of DES, treatment options such as drug-coated balloons or additional stent implantation techniques could be used, but some mechanisms are unique to the BVS, such as BVS recoil, and protruding BVS segments that are formed by the natural degradation of the scaffold. The use of intravascular imaging may give clinicians more information on the pathogenesis of BVS restenosis, and also suggest feasible treatment options for these lesions. 


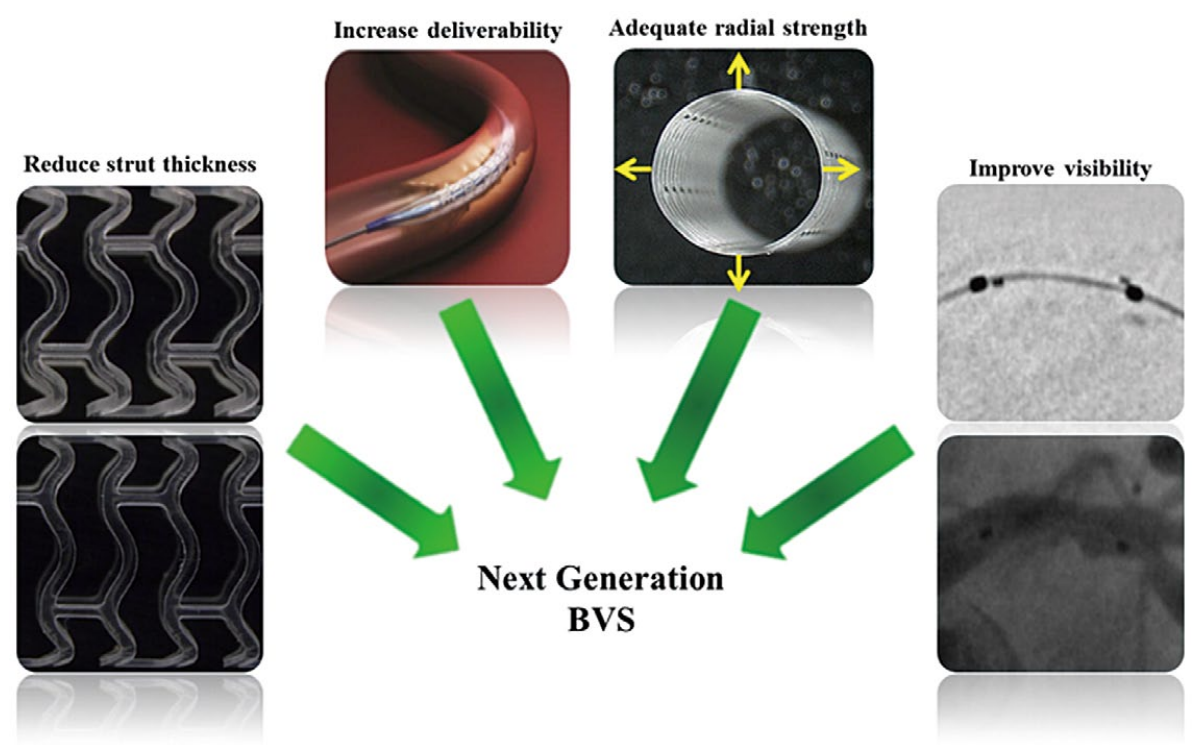

Figure 6. Requirements of an ideal bioresorbable vascular scaffold (BVS).

\section{Intravascular Imaging for BVS Implantation}

Because of the unique characteristics of BVS, intravascular imaging is very important in BVS implantation. Inappropriate implantation of the BVS, such as malapposition, underexpansion or stent fracture, can bring devastating results such as BVS restenosis and ST. Currently, OCT is the best and the most commonly used imaging modality because of its high image resolution capability.

First, in pre-implantation planning OCT can be used to perform more precise device sizing (scaffold diameter and length), which is essential because of the thicker BVS scaffold and limitation in overexpansion compared with DES. Histologic characterization of the plaque is needed to consider the usage of special adjunctive tools, such as scoring balloons or rotational atherectomy. Also, the relationship of the lesion and side braches should be observed to plan accurate scaffold landing zones. After BVS implantation, OCT can evaluate the appropriateness of scaffold apposition, expansion and the presence of dissection or fracture. During follow-up, neointimal formation and the amount of remnant scaffold can be evaluated with OCT to guide optimal medical therapy. Collectively, imaging modalities in BVS implantation can be used to evaluate vessel and lesion characteristics both pre- and post-BVS implantation, as well as during long-term follow-up.

In the near future we will get insights on the value of intravascular imaging in BVS implantation from the few ongoing clinical trials, such as the OPTICO-BVS trial (ClinicalTrials.gov Identifier: NCT02683356), GUIDE-BVS trial (ClinicalTrials.gov Identifier: NCT02831218), and the ACTIV-BVS trial (ClinicalTrials.gov Identifier: NCT02814578).

\section{Antiplatelet Therapy After BVS Implantation}

Adequate duration of DAPT after BVS implantation represents another important issue to be addressed. Appropriate antiplatelet therapy should be more actively considered because of the concern related to higher risk of ST in patients implanted with a BVS. Although various studies currently support the use of DAPT for $<12$ months after implantation of 2nd-generation DES, the same strategy should not be applied to patients implanted with a BVS. Based on currently available data, DAPT should be continued as long as necessary, and potent P2Y12 receptor antagonists (i.e., prasugrel and ticagrelor) should be considered, especially in patients with acute coronary syndrome and increased risk of thrombosis. ${ }^{40}$

Regarding DAPT duration in BVS-implanted patients, a few unique characteristics of BVS should be considered. Because of the properties of PLLA and the increased strut thickness, implanted BVS may show greater strut protrusion, and detached scaffold fragments may act as the nidus of very late thrombosis. ${ }^{27}$ Thus, BVS implantation may require more potent and longer-duration therapy with antiplatelet agents. Given the persistence of residual scaffold until at least 3 years post-implantation and the increased rate of very late ST, DAPT should be continued until the lesion is fully resolved, if there is no situation requiring shorter DAPT. Nevertheless, the optimal duration of DAPT may change with the development of 2ndgeneration BVS, which should provide thinner struts, as well as homogenous stent expansion and apposition.

\section{Development of an Ideal BVS}

Although currently used 2nd-generation DES have dramatically decreased the rate of adverse clinical outcomes after PCI, long-term limitations remain major challenges. Absorbable scaffolds were designed to overcome the limitations of conventional, non-absorbable, metal-based DES. The theoretical benefits of BVS, such as recovery of physiologic vasomotor function, should be achieved using implantation protocols as comfortable as those currently applied for 2nd-generation DES. However, because of the 
relatively short history of BVS, the technology is still in its infancy. Currently used 1st-generation BVS have disadvantages related to scaffold thickness (which limits deliverability), limited overexpansion, and poor radio-opacity. To improve the current implantation protocol, which is cumbersome, new efforts have focused on the development of absorbable metal scaffolds, which are expected to provide superior radial strength, negligible elastic recoil, higher adaptability, and improved visibility under fluoroscopy (Figure 6). ${ }^{14}$ The Magmaris (Biotronik AG, Bulach, Switzerland) is a sirolimus-eluting bioresorbable magnesium scaffold that has better deliverability, radial support and a fast resorption time, and has received the CE mark in 2016. Also, preliminary results of several studies (FANTOM II, MeRes-1, FORTITUDE, and FUTURE-I) assessing various new BVS were recently published. ${ }^{41}$ The findings indicated that new BVS showed favorable angiographic outcomes such as reduced late loss and stable scaffold area. Despite the promising angiographic results, however, long-term follow-up clinical outcomes remain to be evaluated. Other ongoing studies are expected to provide additional answers regarding the efficacy and safety of newly developed BVS. ${ }^{42}$

\section{Conclusions}

In the current and upcoming context of interventional cardiology, the concept of fully resorbable coronary stents and restored vascular function is surely very attractive. The Absorb BVS was shown to be safe and effective in the treatment of CAD and thus received both the CE mark and FDA approval. However, recent data from ongoing trials have indicated that BVS possess several critical drawbacks, including poor radial strength, limited spectrum of application to simple CAD lesions, poor radio-opacity, and higher rate of ST. Additionally, there are still unanswered major issues, such as developing less complex implantation protocols and determining the optimal duration of antiplatelet therapy. Although the newly developed, 2nd-generation BVS are expected to solve several of these drawbacks at least, further technical improvement and long-term clinical data are warranted before BVS implantation is accepted as a routine PCI procedure in the clinical setting.

\section{Funding}

This study was supported by a research grant from Endocor Korea (grant number 800-20150069).

\section{References}

1. Chandrasekar B, Tanguay JF. Platelets and restenosis. J Am Coll Cardiol 2000; 35: 555-562.

2. Bennett MR. In-stent stenosis: Pathology and implications for the development of drug eluting stents. Heart 2003; 89: 218-224.

3. Fischman DL, Leon MB, Baim DS, Schatz RA, Savage MP, Penn I, et al. A randomized comparison of coronary-stent placement and balloon angioplasty in the treatment of coronary artery disease: Stent Restenosis Study Investigators. N Engl J Med 1994; 331: $496-501$.

4. Serruys PW, Strauss BH, Beatt KJ, Bertrand ME, Puel J, Rickards AF, et al. Angiographic follow-up after placement of a self-expanding coronary-artery stent. N Engl J Med 1991; 324: $13-17$.

5. Weisz G, Leon MB, Holmes DR Jr, Kereiakes DJ, Popma JJ, Teirstein PS, et al. Five-year follow-up after sirolimus-eluting stent implantation results of the SIRIUS (Sirolimus-Eluting Stent in De-Novo Native Coronary Lesions) Trial. J Am Coll Cardiol 2009; 53: $1488-1497$.

6. McFadden EP, Stabile E, Regar E, Cheneau E, Ong AT, Kinnaird
$\mathrm{T}$, et al. Late thrombosis in drug-eluting coronary stents after discontinuation of antiplatelet therapy. Lancet 2004; 364: 15191521.

7. Kimura T, Morimoto T, Natsuaki M, Shiomi H, Igarashi K, Kadota K, et al. Comparison of everolimus-eluting and sirolimuseluting coronary stents: 1-year outcomes from the Randomized Evaluation of Sirolimus-eluting Versus Everolimus-eluting stent Trial (RESET). Circulation 2012; 126: 1225-1236.

8. Bangalore S, Toklu B, Amoroso N, Fusaro M, Kumar S, Hannan $\mathrm{EL}$, et al. Bare metal stents, durable polymer drug eluting stents, and biodegradable polymer drug eluting stents for coronary artery disease: Mixed treatment comparison meta-analysis. $B M J$ 2013; 347: f6625.

9. Levine GN, Bates ER, Blankenship JC, Bailey SR, Bittl JA, Cercek B, et al. 2015 ACC/AHA/SCAI Focused Update on Primary Percutaneous Coronary Intervention for Patients with ST-Elevation Myocardial Infarction: An update of the 2011 ACCF/AHA/SCAI Guideline for Percutaneous Coronary Intervention and the 2013 ACCF/AHA Guideline for the Management of ST-Elevation Myocardial Infarction. J Am Coll Cardiol 2016; 67: 1235-1250.

10. Ang HY, Bulluck H, Wong P, Venkatraman SS, Huang Y, Foin N. Bioresorbable stents: Current and upcoming bioresorbable technologies. Int J Cardiol 2017; 228: 931-939.

11. Iqbal J, Onuma Y, Ormiston J, Abizaid A, Waksman R, Serruys P. Bioresorbable scaffolds: Rationale, current status, challenges, and future. Eur Heart J 2014; 35: 765-776.

12. The Society for Cardiovascular Angiography and Interventions' 39th Annual Scientific Sessions. Catheter Cardiovasc Interv 2016; 87(Suppl 2): S1-S169.

13. Onuma Y, Ormiston J, Serruys PW. Bioresorbable scaffold technologies. Circ J 2011; 75: 509-520.

14. Indolfi C, De Rosa S, Colombo A. Bioresorbable vascular scaffolds: Basic concepts and clinical outcome. Nat Rev Cardiol 2016; 13: $719-729$.

15. Serruys PW, Chevalier B, Dudek D, Cequier A, Carrie D, Iniguez $\mathrm{A}$, et al. A bioresorbable everolimus-eluting scaffold versus a metallic everolimus-eluting stent for ischaemic heart disease caused by de-novo native coronary artery lesions (ABSORB II): An interim 1-year analysis of clinical and procedural secondary outcomes from a randomised controlled trial. Lancet 2015; 385: $43-54$.

16. Puricel S, Arroyo D, Corpataux N, Baeriswyl G, Lehmann S, Kallinikou Z, et al. Comparison of everolimus- and biolimuseluting coronary stents with everolimus-eluting bioresorbable vascular scaffolds. J Am Coll Cardiol 2015; 65: 791 -801.

17. Gao R, Yang Y, Han Y, Huo Y, Chen J, Yu B, et al. Bioresorbable vascular scaffolds versus metallic stents in patients with coronary artery disease: ABSORB China trial. J Am Coll Cardiol 2015; 66: $2298-2309$.

18. Kimura T, Kozuma K, Tanabe K, Nakamura S, Yamane M, Muramatsu T, et al. A randomized trial evaluating everolimuseluting Absorb bioresorbable scaffolds vs. everolimus-eluting metallic stents in patients with coronary artery disease: ABSORB Japan. Eur Heart J 2015; 36: 3332-3342.

19. Ellis SG, Kereiakes DJ, Metzger DC, Caputo RP, Rizik DG, Teirstein PS, et al. Everolimus-eluting bioresorbable scaffolds for coronary artery disease. $N$ Engl J Med 2015; 373: 1905-1915.

20. Sabate M, Windecker S, Iniguez A, Okkels-Jensen L, Cequier A, Brugaletta S, et al. Everolimus-eluting bioresorbable stent vs. durable polymer everolimus-eluting metallic stent in patients with ST-segment elevation myocardial infarction: Results of the randomized ABSORB ST-segment elevation myocardial infarction-TROFI II trial. Eur Heart J 2016; 37: 229-240.

21. Serruys PW, Chevalier B, Sotomi Y, Cequier A, Carrie D, Piek $\mathrm{JJ}$, et al. Comparison of an everolimus-eluting bioresorbable scaffold with an everolimus-eluting metallic stent for the treatment of coronary artery stenosis (ABSORB II): A 3 year, randomised, controlled, single-blind, multicentre clinical trial. Lancet 2016; 388: 2479-2491.

22. Stone GW, Gao R, Kimura T, Kereiakes DJ, Ellis SG, Onuma Y, et al. 1-year outcomes with the Absorb bioresorbable scaffold in patients with coronary artery disease: A patient-level, pooled meta-analysis. Lancet 2016; 387: 1277-1289.

23. Capodanno D, Gori T, Nef H, Latib A, Mehilli J, Lesiak M, et al. Percutaneous coronary intervention with everolimus-eluting bioresorbable vascular scaffolds in routine clinical practice: Early and midterm outcomes from the European multicentre GHOST-EU registry. EuroIntervention 2015; 10: 1144-1153.

24. Brugaletta S, Gori T, Low AF, Tousek P, Pinar E, Gomez-Lara 
J, et al. Absorb bioresorbable vascular scaffold versus everolimus-eluting metallic stent in ST-segment elevation myocardial infarction: 1-year results of a propensity score matching comparison: The BVS-EXAMINATION Study (bioresorbable vascular scaffold-a clinical evaluation of everolimus eluting coronary stents in the treatment of patients with ST-segment elevation myocardial infarction). JACC Cardiovasc Interv 2015; 8: 189-197.

25. Genereux P, Rutledge DR, Palmerini T, Caixeta A, Kedhi E, Hermiller JB, et al. Stent thrombosis and dual antiplatelet therapy interruption with everolimus-eluting stents: Insights from the Xience V coronary stent system trials. Circ Cardiovasc Interv 2015; 8: e001362.

26. Lipinski MJ, Escarcega RO, Baker NC, Benn HA, Gaglia MA $\mathrm{Jr}$, Torguson R, et al. Scaffold thrombosis after percutaneous coronary intervention with ABSORB bioresorbable vascular scaffold: A systematic review and meta-analysis. JACC Cardiovasc Interv 2016; 9: 12-24.

27. Colombo A, Ruparelia N. Who Is thrombogenic: The scaffold or the doctor? Back to the future! JACC Cardiovasc Interv 2016; 9: $25-27$.

28. Sotomi Y, Suwannasom P, Serruys PW, Onuma Y. Possible mechanical causes of scaffold thrombosis: Insights from case reports with intracoronary imaging. EuroIntervention 2017; 12: $1747-1756$.

29. Stone GW, Granada JF. Very late thrombosis after bioresorbable scaffolds: Cause for concern? J Am Coll Cardiol 2015; 66: $1915-1917$

30. Sotomi Y, Ishibashi Y, Suwannasom P, Nakatani S, Cho YK, Grundeken MJ, et al. Acute gain in minimal lumen area following implantation of everolimus-eluting ABSORB biodegradable vascular scaffolds or Xience metallic stents: Intravascular ultrasound assessment from the ABSORB II trial. JACC Cardiovasc Interv 2016; 9: 1216-1227.

31. Puricel S, Cuculi F, Weissner M, Schmermund A, Jamshidi P, Nyffenegger T, et al. Bioresorbable coronary scaffold thrombosis: multicenter comprehensive analysis of clinical presentation, mechanisms, and predictors. J Am Coll Cardiol 2016; 67: 921 931.

32. Rizik DG [presenter]. PSP: A synthesis of technique imperatives for Absorb implantation. Presentation 1 November: TCT 2016. https://www.tctmd.com/slide/psp-synthesis-technique-imperatives-absorb-implantation (accessed May 30, 2017).

33. Ortega-Paz L, Capodanno D, Giacchi G, Gori T, Nef H, Latib A, et al. Impact of overlapping on 1-year clinical outcomes in patients undergoing everolimus-eluting bioresorbable scaffolds implantation in routine clinical practice: Insights from the European multicenter GHOST-EU registry. Catheter Cardiovasc Interv 2017; 89: 812-818.

34. Tarantini G, Mojoli M, Masiero G, Cortese B, Loi B, Varricchio $A$, et al. Clinical outcomes of overlapping versus non-overlapping everolimus-eluting absorb bioresorbable vascular scaffolds: An analysis from the multicentre prospective RAI registry (ClinicalTrials.gov identifier: NCT02298413). Catheter Cardio- vasc Interv, doi:10.1002/ccd.27095.

35. Felix CM, Fam JM, Diletti R, Ishibashi Y, Karanasos A, Everaert BR, et al. Mid- to long-term clinical outcomes of patients treated with the everolimus-eluting bioresorbable vascular scaffold: The BVS Expand Registry. JACC Cardiovasc Interv 2016; 9: $1652-$ 1663.

36. Testa L, De Carlo M, Petrolini A, Rapetto C, Varbella F, Cortese $\mathrm{B}$, et al. One-year clinical results of the Italian diffuse/multivessel disease ABSORB prospective registry (IT-DISAPPEARS). EuroIntervention, doi:10.4244/EIJ-D-17-00246.

37. Abizaid A, Ribamar Costa J Jr, Bartorelli AL, Whitbourn R, van Geuns RJ, Chevalier B, et al. The ABSORB EXTEND study: preliminary report of the twelve-month clinical outcomes in the first 512 patients enrolled. EuroIntervention 2015; 10: 1396-1401.

38. Onuma Y, Serruys PW, Perkins LE, Okamura T, Gonzalo N, Garcia-Garcia HM, et al. Intracoronary optical coherence tomography and histology at 1 month and 2,3 , and 4 years after implantation of everolimus-eluting bioresorbable vascular scaffolds in a porcine coronary artery model: An attempt to decipher the human optical coherence tomography images in the ABSORB trial. Circulation 2010; 122: 2288-2300.

39. Elwany M, Latini RA, Di Palma G, Orrego PS, Cortese B. First experience of drug-coated balloons for treatment of bioresorbable vascular scaffold restenosis. Cardiovasc Revasc Med, doi:10.1016/j. carrev.2017.03.020

40. Raber L, Brugaletta S, Yamaji K, O'Sullivan CJ, Otsuki S, Koppara $\mathrm{T}$, et al. Very late scaffold thrombosis: Intracoronary imaging and histopathological and spectroscopic findings. $J \mathrm{Am}$ Coll Cardiol 2015; 66: 1901-1914

41. Geuns R-Jv. Highlights (and my Interpretations) From: New BRS-FANTOM II, MeRes-1, FORTITUDE and FUTURE-I (6-9 Month Results). Presented at TCT 2016. https://www. tctmd.com/slide/highlights-and-my-interpretations-new-brsfantom-ii-meres-1-fortitude-and-future-i-6-9-month (accessed June 29, 2017).

42. Bouchi YH, Gogas BD. Biocorrodible metals for coronary revascularization: Lessons from PROGRESS-AMS, BIOSOLVE-I, and BIOSOLVE-II. Glob Cardiol Sci Pract 2015; 2015: 63.

43. Cassese S, Byrne RA, Ndrepepa G, Kufner S, Wiebe J, Repp J, et al, Everolimus-eluting bioresorbable vascular scaffolds versus everolimus-eluting metallic stents: A meta-analysis of randomised controlled trials. Lancet 2016; 387: 537-544.

44. Zhang XL, Zhu L, Wei ZH, Zhu QQ, Qiao JZ, Dai Q, et al. Comparative efficacy and safety of everolimus-eluting bioresorbable scaffold versus everolimus-eluting metallic stents: A systematic review and meta-analysis. Ann Intern Med 2016; 164: $752-763$.

45. Mukete BN, van der Heijden LC, Tandjung K, Baydoun H, Yadav K, Saleh QA, et al. Safety and efficacy of everolimuseluting bioresorbable vascular scaffolds versus durable polymer everolimus-eluting metallic stents assessed at 1-year follow-up: A systematic review and meta-analysis of studies. Int $J$ Cardiol 2016; 221: 1087-1094. 